\title{
Preventing DNA over-replication: a Cdk perspective
} Andrew CG Porter

\author{
Address: Department of Haematology, Faculty of Medicine, Imperial College London, Du Cane Road, London W12 ONN, UK \\ Email: Andrew CG Porter - andy.porter@imperial.ac.uk
}

Published: 22 January 2008

Cell Division 2008, 3:3 doi:10.1 186/1747-1028-3-3

This article is available from: http://www.celldiv.com/content/3/I/3

(c) 2008 Porter; licensee BioMed Central Ltd.

This is an Open Access article distributed under the terms of the Creative Commons Attribution License (http://creativecommons.org/licenses/by/2.0), which permits unrestricted use, distribution, and reproduction in any medium, provided the original work is properly cited.
Received: 29 December 2007

Accepted: 22 January 2008

\begin{abstract}
The cell cycle is tightly controlled to ensure that replication origins fire only once per cycle and that consecutive S-phases are separated by mitosis. When controls fail, DNA over-replication ensues: individual origins fire more than once per S-phase (re-replication) or consecutive S-phases occur without intervening mitoses (endoreduplication). In yeast the cell cycle is controlled by a single cyclin dependent kinase ( $\mathrm{Cdk}$ ) that prevents origin licensing at times when it promotes origin firing, and that is inactivated, via proteolysis of its partner cyclin, as cells undergo mitosis. A quantitative model describes three levels of Cdk activity: low activity allows licensing, intermediate activity allows firing but prevents licensing, and high activity promotes mitosis. In higher eukaryotes the situation is complicated by the existence of additional proteins (geminin, Cul4-Ddb/Cdt2, and Emil) that control licensing. A current challenge is to understand how these various control mechanisms are co-ordinated and why the degree of redundancy between them is so variable. Here the experimental induction of DNA over-replication is reviewed in the context of the quantitative model of Cdk action. Endoreduplication is viewed as a consequence of procedures that cause Cdk activity to fall below the threshold required to prevent licensing, and re-replication as the result of procedures that increase that threshold value. This may help to explain why over-replication does not necessarily require reduced $\mathrm{Cdk}$ activity and how different mechanisms conspire to prevent over-replication. Further work is nevertheless required to determine exactly how losing just one licensing control mechanism often causes over-replication, and why this varies between cell systems.
\end{abstract}

\section{Background}

DNA over-replication: the result of uncontrolled origin licensing

The two main hallmarks of the eukaryotic cell cycle are the duplication of the genome (S-phase) and segregation of the two resulting copies into two progeny cells (mitosis). In the interests of genome stability, S-phases must alternate with mitoses and must exactly duplicate the genome. Genome duplication involves DNA replication starting at multiple origins, each of which must therefore initiate ('fire') only once per S-phase, and only if preceded by mitosis. To achieve this an origin licensing system has evolved: origins cannot fire without being licensed, and then cannot be re-licensed without passing through mitosis, during which conditions permissive for licensing but not firing are restored [1-3]. Biochemically, licensing refers to the combined action of various factors (ORC, cdc6, Cdt1, MCM2-7) in assembling a pre-replication complex at replication origins, a process that occurs in G1 prior to origin firing in S-phase.

Failures in licensing control can give rise to two basic types of DNA over-replication: endoreduplication and rereplication. (The terminology of Arias and Walter [4] is 
used here, but it should be noted that in many publications, the term re-replication is used more broadly to encompass both re-replication and endoreduplication). In endoreduplication, S-phase is no longer dependent on the passage through mitosis and multiple consecutive Sphases can occur (Fig. 1a,b,c) giving rise to discrete increases in DNA content; within a single S-phase, however, origins still fire only once. Endoreduplication occurs naturally in certain cell types as part of their normal developmental programme [5]. In contrast, re-replicating cells no longer maintain the temporal separation of origin licensing and firing. Thus, during re-replication, origins can fire more than once within a single S-phase leading to a continuous increase in DNA content (Fig. 1d). Re-replication does not appear to occur as part of any natural developmental programme. Experimentally, endoreduplication (at least from G2 or M) and re-replication are usually distinguished by flow cytometric measurements of DNA content, the former giving rise to discrete peaks corresponding to $8 \mathrm{~N}, 16 \mathrm{~N}, 32 \mathrm{~N}$ etc. $(\mathrm{N}=$ haploid chromosome number), the latter generating a range of DNA contents with intermediate values (e.g. between $4 \mathrm{~N}$ and 8 $\mathrm{N})$. Endoreduplication from S-phase is also expected to

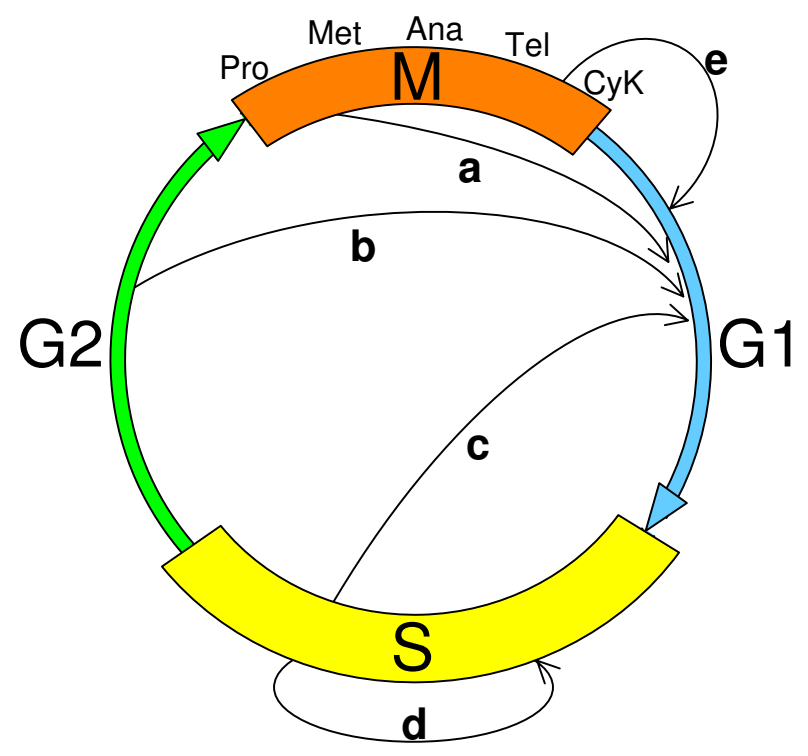

\section{Figure I}

Pathways of over-replication. The GI state required for coordinated origin licensing is normally reached by passing through mitosis. Endoreduplicating cells reach GI from early M (a), G2 (b) or S (c). Re-replication (d) involves a continuous S-phase during which origin licensing and firing are both permitted. Endomitosis (e) occurs when cytokinesis (CyK) is bypassed but does not involve premature licensing. This figure is similar to Fig. 3 in [5] describing naturally occurring endoreduplication. Pro, Met, Ana, Tel refer to prophase, metaphase, anaphase and telophase, respectively. generate intermediate values and so is probably difficult to distinguish from re-replication by this method. Discrete doublings in ploidy do not necessarily indicate endoreduplication; they can also result from failures in cytokinesis (Fig. 1e), but these involve no change in licensing control and will not be considered further here.

\section{Cdk and APC/C: mutually antagonistic drivers of the cell cycle}

The master controllers of the cell cycle are the cyclin dependent kinases $[6,7]$ and the anaphase promotion/ cyclosome (APC/C) complex $[8,9]$. When heterodimerised with their cyclin partners, which are periodically degraded at various points during the cell cycle, Cdks promote both S-phase and mitosis by phosphorylating key target proteins. The single $\mathrm{Cdk}$ in fission and budding yeast (Cdc2 and Cdc28 respectively; hereafter Cdk1) associates with multiple cyclins but, at least in fission yeast, a viable cell cycle can be supported by a single cyclin [10]. In budding yeast, cells with deletions in all six B-type cyclin genes [11] or in all three G1-type cyclin genes [12] can be rescued by expression of a single B-type cyclin gene.

In higher eukaryotes multiple Cdks and cyclins exist, the key combinations being Cdk1/cyclin A and B at mitosis, Cdk1 and 2/cyclin A and E during G1/S and Cdk4 and 6/ cyclin D during G1 [6]. While different Cdk/cyclin combinations are required in specific lineages during development, accumulating evidence [13-18], particularly the recent generation of viable mouse embryo fibroblasts (MEFs) deleted for Cdk2, Cdk4 and Cdk6 [19], indicates that Cdk1 is the only major Cdk that is absolutely required for viable cell cycles. Furthermore, in frog egg extracts mitotic cyclins are capable of supporting S-phase functions $[20,21]$, and the major cyclin genes can be individually deleted in mice without completely preventing cell proliferation [22]. It has yet to be determined, however, whether higher eukaryotes can, like fission yeast, support viable cell cycles with just a single cyclin/Cdk1 combination.

The counterbalance to Cdk activity is provided by the APC/C, a ubiquitin ligase complex which has many substrates but most crucially targets mitotic cyclins at anaphase for degradation $[8,9]$. This effectively eliminates Cdk activity, allowing for a period (late M and G1) that is permissive for origin licensing. For the rest of the cell cycle ( $\mathrm{S}$, G2 and early M) APC/C must be inactivated, so that mitotic cyclins (A and B) can re-accumulate, and this is achieved (at least in part; see below) by inhibitory, Cdkmediated phosphorylation of Cdh1, the G1 activating subunit of APC/C. During mitosis, however, high Cdk1 activity activates another APC/C activator, Cdc20, leading to the destruction of mitotic cyclins that allows mitotic exit and activation of APC/CCdh1 $\mathrm{APC} / \mathrm{C}$ and $\mathrm{Cdk}$ are thus 
mutually antagonistic and the cell cycle oscillates between periods dominated by APC/C or Cdk activity.

\section{DNA over-replication and the quantitative model of Cdk action in yeast}

In addition to its roles in promoting $\mathrm{S}$ phase and mitosis, Cdk has a third role: preventing DNA over-replication. This role was revealed in fission yeast when a temperature sensitive Cdk1 allele was transiently heat-inactivated after G2 arrest, causing the cells to bypass mitosis, to 'reset' in G1 and undergo a second S-phase [23]. Furthermore, multiple consecutive S-phases could be induced by deletion of Cdc13 [24], which encodes the mitotic cyclin partner of Cdk1, or by over-expression or Rum $1[25,26]$, an inhibitor of Cdk1 in G2. Such endoreduplication was demonstrated by discrete doublings in the genome size. Similar results were obtained in budding yeast [27].

The problem of how a single Cdk could suppress over-replication yet also promote S-phase and M-phase was addressed in the quantitative model of Cdk action $[10,28]$. It was proposed that, following exit from mitosis, rising levels of Cdk activity pass through two thresholds. Below the first threshold $\left(T_{S}\right)$, in $G 1$, replication origins can be licensed but cannot fire, but above $T_{S}$ origins can fire but cannot be re-licensed. Thus transition above $T_{S}$ marks the beginning of S-phase and ensures that origins fire only once per S-phase. The second threshold $\left(T_{M}\right)$ is passed when inhibitory phosphorylation sites on Cdk1 are removed by Cdk1-activated Cdc25 phosphatase, resulting in a highly activated Cdk1 that promotes the onset of mitosis [29]. Destruction of mitotic cyclins by the $\mathrm{APC} / \mathrm{C}$ allows mitotic exit and completes the cycle (Fig. 2A).

Although the quantitative model is strongly supported by the observation that a single cyclin/Cdk1 complex can guide the cell cycle of fission yeast [10], a degree of qualitative control is also evident. Thus, individual cyclin/Cdk combinations are known to have specific functions $[3,30,31]$ and these are likely to contribute to the fine tuning of cell cycle control, especially in higher vertebrates.

Endoreduplication is explained in the context of the quantitative model as follows (Fig. 2B,C). In G2, or early $M$, experimental depletion of Cdk activity causes premature activation of $\mathrm{APC} / \mathrm{C}^{\mathrm{Cdh}} 1$, without the need to traverse mitosis and activate $\mathrm{APC} / \mathrm{C}^{\mathrm{Cdc} 20}$. The cells therefore reset in G1, co-ordinately relicense all origins and, when Cdk is reactivated, enter the next S-phase. For multiple endocycles, the loss of Cdk activity must be repeated each time the cells reach G2/M. This can be achieved experimentally, (e.g. by repeated temperature shifts in tsCdk1 mutants) or spontaneously, by residual cell cycle oscillations. Thus, multiple endocycles seen after Cdc13 deletion in fission yeast reflect the periodic synthesis and inactivation of the S-phase cyclins. In principle, those cells in S-phase at the time of Cdk1 depletion should also reset in G1 (Fig 2D), in which case restoration of Cdk1 activity would lead to duplication of a partially replicated genome, i.e. discrete but variable increases in ploidy to less than $8 \mathrm{~N}$. This form of endoreduplication does not appear to have been described after the experimental depletion of Cdk1 activity, possibly because of difficulties in distinguishing it on the basis of DNA content from other forms of over-replication, but it does occur naturally in Drosophila larval tissue [5].

To describe re-replication in terms of the quantitative model it is important to remember that, by definition, it involves conditions that simultaneously permit both origin licensing and firing. Multiple overlapping mechanisms by which Cdk1 can prevent origin licensing in yeast have been revealed. These include inhibition of ORC, nuclear export of Cdt1 and MCM2-7, and inactivation, degradation and reduced synthesis of Cdc6 ([32]; see [4] for a recent review). More recently the essential Cdk1 substrates (Sld2, Sld3) whose phosphorylation leads to origin firing have been identified [33]. These studies do not appear to indicate that the threshold Cdk activities for inhibiting origin licensing $\left(\mathrm{T}_{\mathrm{L}}\right)$ and for promoting origin firing $\left(\mathrm{T}_{\mathrm{F}}\right)$ need necessarily coincide. The possibility therefore exists that these are independent thresholds and that, under normal circumstances, parameters are set such that $\mathrm{T}_{\mathrm{F}}>\mathrm{T}_{\mathrm{L}}$. In this model, re-replication is caused by any procedure that disturbs such parameters to cause $T_{F}<T_{L}$ (Fig. $2 \mathrm{E}$ ). In budding yeast, multiple components of the preRC complex are sensitive to Cdk1 phosphorylation and so conspire to keep $\mathrm{T}_{\mathrm{L}}$ low, but when enough of the relevant phosphorylation sites are mutated, re-replication follows [32]. Alternatively, modifications to Sld2 and Sld 3 that remove their dependence on phosphorylation by $\mathrm{Cdk} 1$, effectively reduce the value of $\mathrm{T}_{\mathrm{F}}$ and so cause re-replication [33].

This proposed separation of $T_{S}$ into separate thresholds $\left(\mathrm{T}_{\mathrm{F}}\right.$ and $\left.\mathrm{T}_{\mathrm{L}}\right)$ has the additional attraction that it predicts an 'insulation' period at the G1/S transition, and also at anaphase, during which origins can neither be licensed nor fire, ensuring that there is no overlap between periods of origin licensing and firing (Fig. 2F). Although insulation in budding yeast has been elegantly explained in terms of different cyclin specificities [3], this quantitative model is potentially more appropriate in fission yeast, at least, where viable cycles require only a single $\mathrm{Cdk} / \mathrm{cyclin}$ combination.

How far can these descriptions of endoreduplication and re-replication in yeast be applied in mammalian cells? 
A

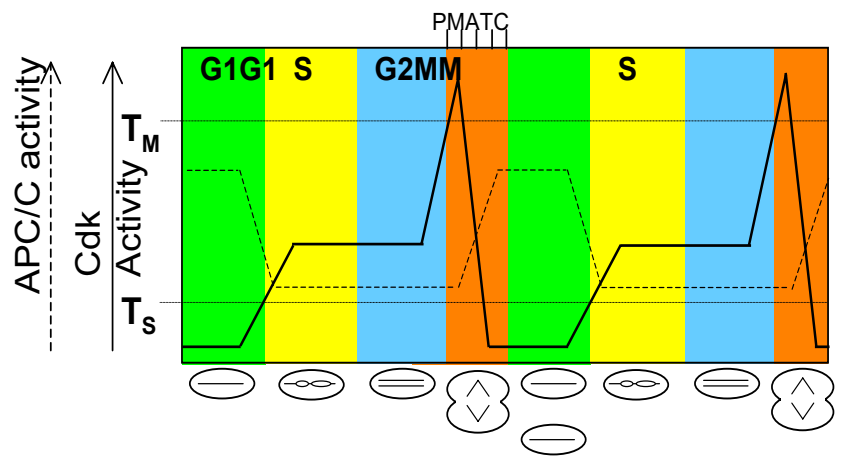

B

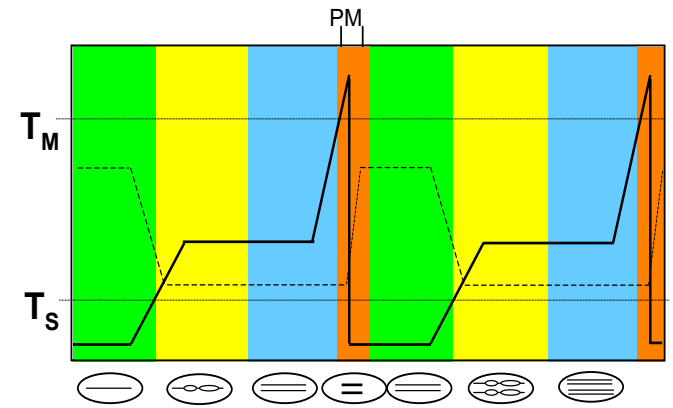

C

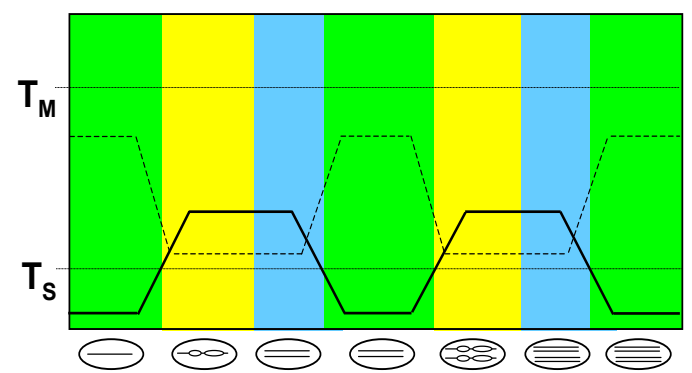

D

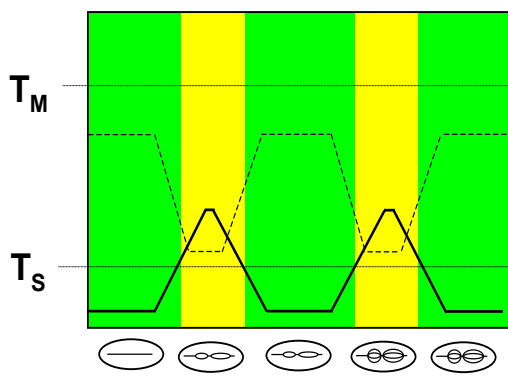

E

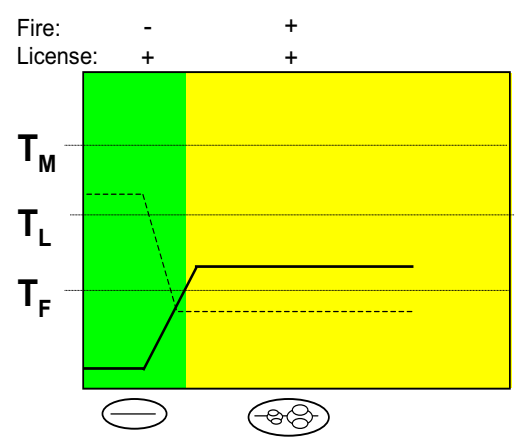

$\mathbf{F}$

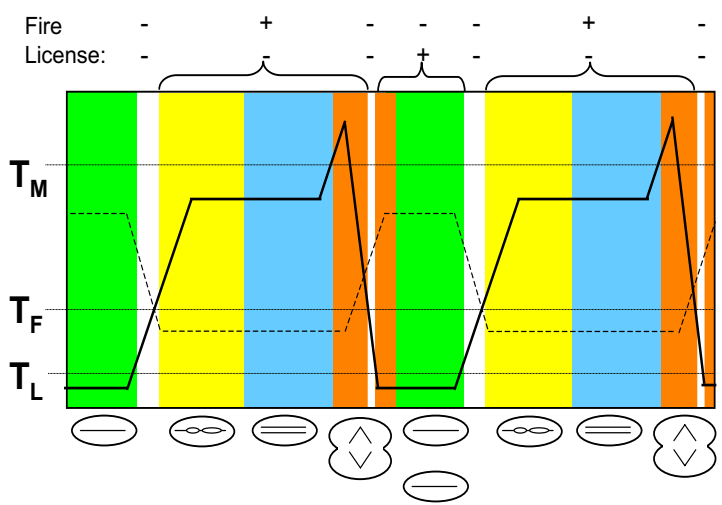

Figure 2

Quantitative model of Cdk activity applied to normal and over-replicating cell cycles. Cdk (continuous line) and APC/C (broken line) activities ( $y$-axis) are plotted against time ( $x$-axis). $T_{M}, T_{S}, T_{L}$ and $T_{F}$ indicate thresholds of Cdk activity, as defined in the text. P,M,A,T and C: prometaphase, metaphase, anaphase telophase and cytokinesis, respectively. A. Normal cycle. B. Endoreduplication from mitosis. C. Endoreduplication from G2. D. Endoreduplication from S-phase. E. Re-replication. F. Normal cell cycle with periods of insulation (white segments) when origins can neither be licensed nor fire. Fire $+/-=$ sufficient/insufficient Cdk to promote origin firing. License $+/-=$ sufficient/insufficient Cdk to prevent licensing.

\section{Endoreduplication from G2 or M after CdkI inactivation in mammalian cells}

By analogy with the work in yeast, experimental depletion of Cdk1 in higher eukaryotes might be expected to promote endoreduplication and this is indeed the case in some cell lines. Thus endoreduplication was seen in human fibrosarcoma cells (HT2-19) with repressible Cdk1 gene expression [34] and in human osteosarcoma (U2OS) cells depleted of Cdk1 by RNA interference [35].
Because Cdk1 depletion was sustainable in these studies, it was possible to detect multiple endocycles, generating ploidies as high as $64 \mathrm{~N}$. (In contrast to yeast, multiple endocycles do not require multiple transient Cdk1 inactivations because S-phases do not require Cdk1.) These endocycles apparently correspond to endoreduplication from G2 (Fig. 2C), bypassing mitosis but maintaining normal S-phases. Thus endoreduplicating HT2-19 cells do not undergo nuclear envelope breakdown or activate the 
APC/CCdc20, but retain cycles of cyclin E expression and centrosome duplication [36]. Also consistent with the model in Fig. 2C is the ability of Cdk1 that lacks inhibitory phosphorylation sites, and is therefore unresponsive to Cdc25 phosphatase, to prevent endoreduplication in HT2-19 without promoting mitosis [37].

Endoreduplication is sometimes seen after DNA damage and this may also be explained in terms of reduced Cdk1 activity [38]. Although G2 checkpoint pathways are known to prevent Cdk1 activation by preventing the removal of inhibitory phosphorylations [39], this is only predicted to prevent Cdk1 levels from exceeding the $T_{M}$ threshold, and so to prevent mitosis. However, sufficiently intense or sustained levels of DNA damage can cause transcriptional silencing of various genes expressed in S/G2, including Cdk1 $[38,40]$, and this more easily explains DNA damage-induced endoreduplication. Cdt1 is also degraded in response to DNA damage by the Cdkindependent Cul4-Ddb1 ${ }^{\mathrm{Cdt} 2}$ pathway ([4];see below) and this effect is presumably lost in cells that over-replicate in response to DNA damage.

Endoreduplication has also been observed (in SaOS cells) after indirectly depleting Cdk1 activity with high levels of the Cdk inhibitors p21 or p27 [41,42] or (in HCT-116 cells) with siRNA to cyclin B [43]. Endoreduplication in response to Cdk inhibitor over-expression was found to occur in cells (SaOS, HeLa and in Rb-/-MEFs) lacking functional Retinoblastoma protein $(\mathrm{Rb})$ but not in control cells (Rb+/-MEFs, RKO, Rat1, A549, H1299, HaCat, SW480) with a functional $\mathrm{Rb}$ [41]. This is expected if endoreduplicating cells reset in G1 because Cdk inhibition at this stage would prevent the Rb phosphorylation required to release the E2F transcription factor necessary for the G1/S transition. Cyclin B-depleted HCT116 cells still show signs of early mitosis, presumably due to Cdk1/ cyclin A activity, but they exit mitosis before metaphase [43].

In some studies, involving NCI-H1299 [35] or HeLa and HePG2 cells [44], appreciable endoreduplication required depletion of both cyclin A and B, or both Cdk1 and Cdk2. There is evidence that $\mathrm{Cdk} 2 /$ cyclinA can promote Cdk1 activation [45] and this may help to explain the enhanced phenotype after cyclin A depletion. It is less easy to explain how depleting Cdk2 activity, including Cdk2/ cyclinA, can promote endoreduplication when it is essential for origin firing in the absence of Cdk1. It is possible, however, that Cdk4 or Cdk6 can substitute for Cdk2 at G1/S, as Cdk1 is capable of doing [14,46]. Alternatively, depletion of cyclin A or Cdk2 in these studies may have been more effective at inactivating Cdk1 than Cdk2.
It is notable than in none of the above studies was there any clear evidence of re-replication i.e. of partial rather than discrete increases in ploidy. This is consistent with the models of Fig. 2 because changes in Cdk activity are not predicted to alter the values $\mathrm{T}_{\mathrm{F}}$ and $\mathrm{T}_{\mathrm{L}}$. However, partial increases in ploidy might have been expected if endoreduplication had been induced from S-phase, suggesting that other pathways prevent endoreduplication during S-phase.

There are several mechanisms by which Cdk activity may inhibit origin licensing (reviewed in [4]). The clearest seems to be degradation of Cdt1 by the SCFSkp2 pathway in response to its phosphorylation by Cdk, particularly in G2 $[47,48]$. Also there are data to suggest that the binding of Cdt1 [49,50], ORC and cdc6 [51-54] may each be subject to control by Cdk activity. If sufficient Cdk target sites in the licensing machinery can be mutated, this would be expected to increase the value of $\mathrm{T}_{\mathrm{L}}$ and induce re-replication, but only if Cdk-independent mechanisms of inhibiting licensing are also inactivated (see below). The importance of Cdt 1 and Cdc 6 as targets for the control of re-replication was demonstrated by the re-replication seen when Cdt1 and Cdc6 were over-expressed in H1299 cells [55].

\section{Cells that do not over-replicate after Cdkl inactivation}

Contrasting with the above studies are reports of cell lines where Cdk1 depletion does not result in over-replication. Thus Cdk1 depletion by siRNA failed to induce over-replication in NCI-H1299 cells [35], although as already mentioned, co-depletion of Cdk2 induced endoreduplication. FT210 cells, whose endogenous Cdk1 protein is temperature-sensitive, arrested in G2 at non-permissive temperature; no over-replication was seen $20 \mathrm{~h}$ after temperature-shift [56], but it would be interesting to know the situation at later times. Similarly, chemical inhibition of Cdk1 in asynchronous cultures of HeLa, SW480 or HCT116 cells for 20 h [57], or DT40 cells for 48 h [18], caused only a G2 arrest. In all these cell lines, however, including FT210, Cdk1 inactivation after presynchronisation in mitosis by treatment with nocodazole, did lead to endoreduplication. Thus, in these cell lines, Cdk1 appears to be alone in suppressing endoreduplication during early mitosis, but not in G2. A formal, and potentially interesting explanation for why endoreduplication from G2 is seen after Cdk1 depletion but not after chemical inactivation, would arise if a kinase-independent property of Cdk1 were capable of suppressing endoreduplication in G2. The results in FT210 cells, where Cdk1 is degraded at the non-permissive temperature, argue against this, and a less radical explanation involving Emi1 has recently emerged (see below). Nevertheless, a direct comparison in the same cells of the effects of Cdk1 depletion and inhibition would be valuable. Whatever the outcome, these 
results indicate that, in several cell lines, Cdk1 activity is not alone in being able to suppress licensing in interphase, a conclusion that has been reached by several other lines of investigation.

\section{Geminin and Cul4-Ddb /Cdt2 suppress over-replication by regulating Cdt I}

Geminin is a protein present in metazoans, but not in yeast, that suppresses origin licensing through its ability to bind and inactivate Cdt1 [58,59]. Geminin is stable during S, G2 and early $M$, but targeted for degradation by $\mathrm{APC} / \mathrm{C}$ and therefore degraded during mitosis, allowing for origin licensing until it is resynthesised in late G1. Two pathways target Cdt 1 for degradation. The Cul4-Ddb1 Cdt2 pathway requires Cdt1 to interact with PCNA and therefore operates only in S-phase, but is apparently independent of Cdk activity. This contrasts with Cdt 1 degradation by SCFSkp2, which operates mainly in S/G2/M and, as mentioned above, depends on phosphorylation of Cdt1 by Cdk1. By reducing the amount of free Cdt1, these mechanisms both effectively reduce the level of Cdk activity required to suppress licensing, i.e. reduce the value of $\mathrm{T}_{\mathrm{L}}$, during S, G2 and early mitosis. Initially these mechanisms may have evolved to further reduce the chances of premature re-licensing and to improve the 'insulation' during transitions between phases of high Cdk1 activity and high APC/C activity. Over time, however, mammalian cells have apparently become dependent on them to ensure that $\mathrm{T}_{\mathrm{L}}<\mathrm{T}_{\mathrm{F}}$. Thus, depletion of geminin (in S/G2/ $\mathrm{M}$ ) or Cdt2 (in S) may be sufficient to raise the value of $T_{L}$ above that for $\mathrm{T}_{\mathrm{F}}$ and so cause re-replication. Accordingly, depletion of geminin in HCT116, U2OS and TIG3 cells [60-62], and Cdt2 [63]or Ddb1 [64] in HeLa cells, all cause over-replication characterised by the partial increases in ploidy expected for re-replication. Geminin depletion in HeLa and MCF10A cells does not cause overreplication $[60,65,66]$, however, suggesting that the Cul4Ddb1 ${ }^{\text {Cdt2 }}$ pathway plays the predominant role in these cells during $S$ phase. In mouse embryos, geminin downregulation is associated with endoreduplication and the formation of polyploid cells of the trophoblast lineage [67], rather than with re-replication, suggesting that other pathways prevent licensing during S-phase.

Interestingly, over-replication (apparently involving a mix of partial and discrete increases in ploidy) is seen after geminin depletion in HeLa cells if cyclin A is also depleted (cyclin A depletion alone causing very modest endoreduplication)[60]. It is also notable that in cases where overreplication was caused by geminin or Cdt 2 depletion it was less pronounced when DNA damage-induced checkpoints that lead to Cdk1 inactivation were blocked with caffeine $[61,62]$. A possible explanation for these observations is that in some cells, even when $\mathrm{T}_{\mathrm{L}}>\mathrm{T}_{\mathrm{F}}$, Cdk activity must be limited so that it stays between these two thresh- old values in order for appreciable re-replication to occur. The question remains, however, of why the Cul4Ddb1 ${ }^{\text {Cdt2 }}$ pathway in HeLa cells, whose inhibition is sufficient to cause re-replication $[63,64]$, does not prevent rereplication after the combined depletion of geminin and cyclin A[60]. The possibility should be considered, therefore, that the over-replication caused by depleting both geminin and cyclin A is primarily endoreduplication and that apparent partial increases in ploidy reflect a secondary phenomenon (e.g. apoptosis) and not re-replication.

While the roles of geminin and the Cul4-Ddb1 ${ }^{\mathrm{Cd} 2}$ pathway in suppressing licensing clearly overlap with the role of Cdk1, there are difficulties in explaining how they could be responsible for suppressing origin licensing in those cases where Cdk1 depletion does not cause endoreduplication. This is because Cdk1 depletion is expected to result in $\mathrm{APC} / \mathrm{C}$ activation, at least in $\mathrm{G} 2 / \mathrm{M}$, and therefore geminin degradation, while the Cul4-Ddb1 ${ }^{\mathrm{Cd} t} 2$ pathway only operates in S-phase. The solution to this problem appears to lie with Emi1.

\section{Emil suppresses over-replication by inhibiting APC/C}

Just as the role of Cdk in suppressing licensing is supported by the actions of geminin and the Cul4-Ddb1Cdt2 pathway, so its role in suppressing APC/C during $S$ and G2 is assisted by Emi1. Emi1 is an APC/C inhibitor that interacts with Cdc20 [68] and Cdh1 [69,70]. It is synthesised when the transcription factor E2F is activated at the G1/S boundary [69] and degraded by SCF-dependent proteolysis early in mitosis promoted by Plk1[71]. Emi1 therefore keeps APC/CCdh1 inactive during S and G2, allows mitotic cyclins and geminin to accumulate. In two recent studies where Emi1 was depleted by siRNA in MCF10A, HCT116 and HeLa cells, over-replication was observed, accompanied by reduced levels of cyclins A and B1 and geminin $[60,72]$.

This newly established role for Emi1 may help to explain the different responses between cell lines to Cdk1 inactivation. In some cell lines Emi1 may be sufficiently abundant or available to prevent APC/C activation during S/ $\mathrm{G} 2$, even when Cdk1 is inactive. For example, it was only in mitosis, when Emi1 is degraded, that Cdk1 inhibition caused endoreduplication in various cell lines $[18,57]$. In G2, despite Cdk1 inactivation, geminin was stable and $\mathrm{APC} / \mathrm{C}$ remained inactive [18]. In others cell lines, such as HT1080, however, Emi1 presumably plays a less decisive role than Cdk1 in preventing APC/C activation because Cdk1 depletion causes endoreduplication from G2 $[34,35]$. Further work is required to test the validity of this explanation and to determine the basis of any differences in Emi1 function between cell lines. 
The over-replication seen after Emi1 depletion in HeLa and HCT116 cells appears mainly to involve partial increases in ploidy, suggestive of re-replication [60,72]. This is somewhat puzzling because activation of APC/C following Emi1 depletion is expected to reset cells in a G1like state and so cause endoreduplication. Also, in HeLa cells at least, the Cul4-Ddb1 ${ }^{\mathrm{Cd} 2} 2$ pathway should be capable of preventing origin licensing in S-phase, and therefore re-replication. The phenotype in Emi1-depleted MCF10A is more suggestive of endoreduplication [60], however, and it will be interesting to characterise in more detail, and in more cells lines (including non-transformed cells), the nature of the over-replication caused by Emi1 depletion.

\section{Overview of over-replication control}

The key factors that regulate origin licensing and therefore DNA over-replication at various stages of the vertebrate cell cycle are summarised in Fig. 3. The central role of Cdk is evident, involving not only its ability to inhibit APC/ Cdh1 but also the licensing machinery. It can also be seen how APC/C (and therefore Emi1) is crucial in licensing control because of its role in depleting both geminin and, via cyclin degradation, Cdk1/2 activity [73]. Thus we can see how depleting Cdk activity in mitosis (and in G2 if Emi1 is inactive), or promoting $\mathrm{APC} / \mathrm{C}^{\mathrm{Cdh}} 1$ activity, can cause endoreduplication by reprogramming cells into a G1-like state without the need to pass through mitosis.

Less clear from this summary is how altering just one of the multiple mechanisms for licensing inhibition so often leads to re-replication, and how this can differ between cell lines. The simplest explanation is perhaps that different inhibitory mechanisms contribute unequally and that the balance of contributions is 'set' differently in different cell lines. The example has already been made of how variations in Emi1 availability might explain different responses to Cdk1 inhibition. In another example, we may explain the re-replication caused by geminin depletion in HCT116 cells [60-62] by assuming that Cdk and the Cul4-Ddb1Cdt2 pathway play relatively minor roles, at least in S-phase. The quantitative model of Cdk action can be a useful way of viewing this: geminin is essential to ensure $\mathrm{T}_{\mathrm{L}}<\mathrm{T}_{\mathrm{F}}$ in such cells, whereas the Cul4-Ddb1 ${ }^{\mathrm{Cd} t 2}$ pathway is not. Conversely, in HeLa cells, where depletion of Cul4-Ddb1 ${ }^{\mathrm{Cd} 2} 2$ pathway causes re-replication $[63,64]$, the Cul4-Ddb1 $1^{\text {Cdt2 }}$ pathway is essential to ensure $T_{\mathrm{L}}<\mathrm{T}_{\mathrm{F}}$, whereas geminin is not.

Such explanations need to be tested in detail, but even if they are true, difficult questions remain. Why, for example, do HeLa cells appear to re-replicate when both geminin and cyclin A are depleted [60] when other experiments $[63,64]$ indicate that the Cul4-Ddb1Cdt2 pathway in HeLa cells should prevent this? Also, why is rereplication seen after depletion of Emi1 or of geminin and cyclin A $[60,72]$, when these treatments are expected to reset cells in a G1-like state and so cause endoreduplication, as seen after Cdk depletion $[34,35,41,42]$ ? There are also technical issues concerning the methods for inactivating licensing control mechanisms and for measuring responses. Is it possible, for instance, that the transient and often incomplete nature of siRNA mediated depletion could generate some misleading phenotypes, and how reliable is flow cytometry as a method for distinguishing endoreduplication and re-replication?

Clearly the scheme in Fig. 3 is just a working model and further mechanisms, and/or links between them, are likely to emerge. In fact cross-talk between mechanisms
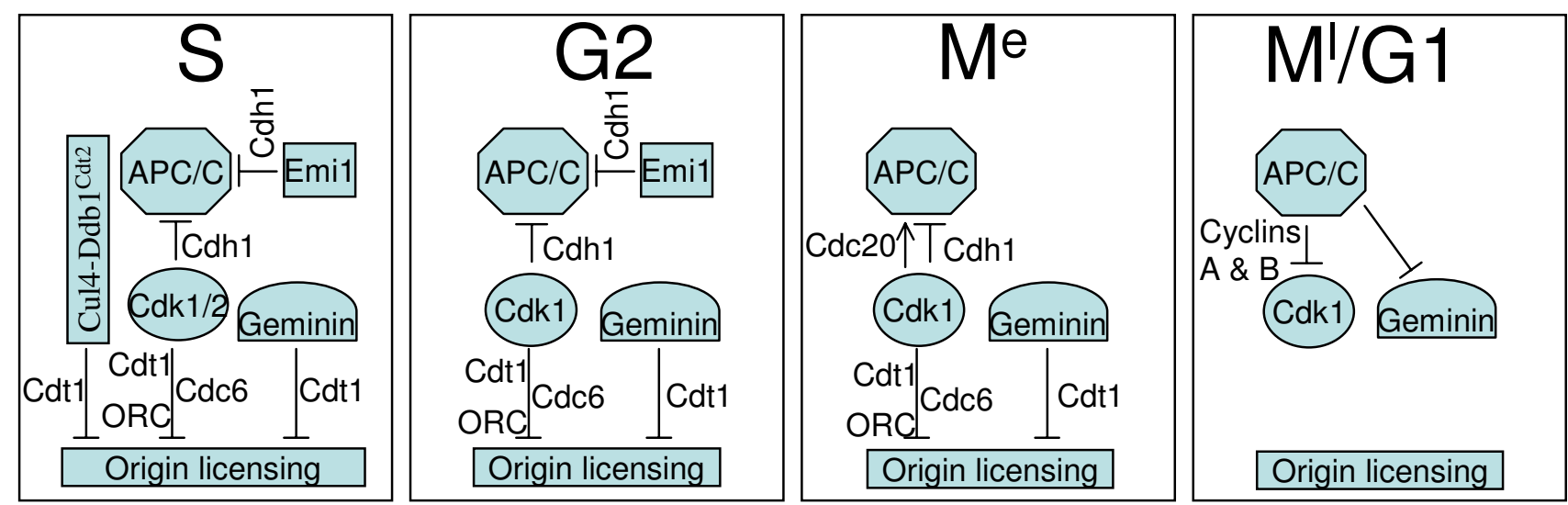

Figure 3

Key regulators of over-replication higher eukaryotes. The relationships between Cdk, APC/C, geminin, Cul4-Ddb ICdt2 and Emil during different cell cycle phases are summarised. $\mathrm{Me}^{\mathrm{e}}$ and $\mathrm{M}$ ', early and late mitosis, respectively. 
has been proposed as way to ensure that disruption of just one mechanism causes massive re-replication rather than partial re-replication; the former would lead to apoptosis, the latter to viable cells with genome damage that may eventually threaten the whole organism [4]. To explore such ideas, future work will require detailed comparisons, both within a single cell system and between different cell systems, of the effects of inhibiting each of the mechanisms identified to date.

\section{Conclusion}

The quantitative model of Cdk action remains a useful starting point for considering how DNA over-replication is prevented, even in higher eukaryotes. Thus endoreduplication may be caused by procedures (e.g. Cdk inhibition or loss of APC/C inhibition) that flip the balance of $\mathrm{Cdk}$ and $\mathrm{APC} / \mathrm{C}$ activities from a $\mathrm{Cdk}^{\text {hi }} / \mathrm{APC}^{\text {lo }}$ state to a $\mathrm{Cdk}^{\mathrm{lo}} / \mathrm{APChi}, \mathrm{G} 1-\mathrm{like}$ state. In some systems this balance may be delicately set, such that a single perturbation is sufficient to promote endoreduplication, in others a combination of perturbations may be required. Similarly, rereplication may be caused by procedures that raise the threshold of Cdk activity required to prevent origin licensing above that required to promote origin firing. The balance of mechanisms that determine these thresholds values is also likely to vary between cell systems such that loss of one mechanism may be sufficient to cause re-replication in one system, whereas in other systems more that one mechanism must be impaired. While these explanations are consistent with many features of experimentally induced over-replication, several inconsistencies remain and these explanations will remain speculative until more information, qualitative and quantitative, is obtained on the various mechanisms that control origin licensing.

\section{Cell lines}

Cells referred to in this article (human, unless stated otherwise): A549 (lung carcinoma), DT40 (Chicken B-cell), FT210 (mouse mammary carcinoma with tsCdk1), HaCat (keratinocyte), HCT116 (colon carcinoma), HeLa (cervical carconoma), Hep3B (liver carcinoma), HT1080 (fibrosarcoma), HT2-19 (HT1080 with IPTG-regulated Cdk1), MEFs (mouse embryo fibroblasts), NCI-H1299 (nonsmall cell lung cancer), MCF10A (immortalised breast epithelial), Rat1 (rat 3T3-like fibroblasts), RKO (colon carconoma), SaOS (osteosarcoma), SW480 (colon adenocarcinoma), TIG3 (normal diploid fibroblasts), U2OS (osteosarcoma).

\section{Abbreviations}

APC/C: anaphase promotion complex/cyclosome; Cdk: cyclin dependent kinase

\section{Competing interests}

The author(s) declare that they have no competing interests.

\section{Acknowledgements}

I am grateful to Helfrid Hochegger and Jaqueline Hayles for helpful comments on the manuscript and to Cancer Research UK and the Medical Research Council for support.

\section{References}

I. Blow J], Hodgson B: Replication licensing--defining the proliferative state? Trends Cell Biol 2002, I 2:72-78.

2. Blow JJ, Dutta A: Preventing re-replication of chromosomal DNA. Nat Rev Mol Cell Biol 2005, 6:476-486.

3. Diffley JF: Regulation of early events in chromosome replication. Curr Biol 2004, 14:R778-86.

4. Arias EE, Walter JC: Strength in numbers: preventing rereplication via multiple mechanisms in eukaryotic cells. Genes Dev 2007, $21: 497-518$.

5. Edgar BA, Orr-Weaver TL: Endoreplication cell cycles: more for less. Cell 200I, 105:297-306.

6. Morgan DO: Cyclin-dependent kinases: engines, clocks, and microprocessors. Annu Rev Cell Dev Biol 1997, I3:26I-29I.

7. Malumbres $M$, Barbacid $M$ : Mammalian cyclin-dependent kinases. Trends Biochem Sci 2005, 30:630-64I.

8. Acquaviva $C$, Pines J: The anaphase-promoting complex/cyclosome: APC/C. J Cell Sci 2006, I I 9:240I-2404.

9. Peters JM: The anaphase promoting complex/cyclosome: a machine designed to destroy. Nat Rev Mol Cell Biol 2006, 7:644-656.

10. Fisher DL, Nurse P: A single fission yeast mitotic cyclin B p34cdc2 kinase promotes both S-phase and mitosis in the absence of G I cyclins. Embo J 1996, 15:850-860.

II. Haase SB, Reed SI: Evidence that a free-running oscillator drives GI events in the budding yeast cell cycle. Nature 1999, 40I:394-397.

12. Epstein CB, Cross FR: CLB5: a novel B cyclin from budding yeast with a role in S phase. Genes Dev 1992, 6:1695-1706.

13. Berthet C, Kaldis P: Cell-specific responses to loss of cyclindependent kinases. Oncogene 2007, 26:4469-4477.

14. Bashir T, Pagano M: Cdk I: the dominant sibling of Cdk2. Nat Cell Biol 2005, 7:779-78I.

15. Malumbres M: Revisiting the "Cdk-centric" view of the mammalian cell cycle. Cell Cycle 2005, 4:206-210.

16. Ortega S, Prieto I, Odajima J, Martin A, Dubus P, Sotillo R, Barbero $J L$, Malumbres M, Barbacid M: Cyclin-dependent kinase 2 is essential for meiosis but not for mitotic cell division in mice. Nat Genet 2003, 35:25-31.

17. Pacek M, Prokhorova TA, Walter JC: CdkI: unsung hero of $\mathbf{S}$ phase? Cell Cycle 2004, 3:40I-403.

18. Hochegger H, Dejsuphong D, Sonoda E, Saberi A, Rajendra E, Kirk J, Hunt T, Takeda S: An essential role for Cdk I in S phase control is revealed via chemical genetics in vertebrate cells. J Cell Biol 2007, 178:257-268.

19. Santamaria D, Barriere C, Cerqueira A, Hunt S, Tardy C, Newton K, Caceres JF, Dubus $P$, Malumbres M, Barbacid M: CdkI is sufficient to drive the mammalian cell cycle. Nature 2007, 448:8II-8I5.

20. Prokhorova TA, Mowrer K, Gilbert CH, Walter JC: DNA replication of mitotic chromatin in Xenopus egg extracts. Proc Natl Acad Sci U S A 2003, 100:13241-13246.

21. Moore JD, Kirk JA, Hunt T: Unmasking the S-phase-promoting potential of cyclin B I. Science 2003, 300:987-990.

22. Ciemerych MA, Sicinski $P$ : Cell cycle in mouse development. Oncogene 2005, 24:2877-2898.

23. Broek D, Bartlett R, Crawford K, Nurse P: Involvement of p34cdc2 in establishing the dependency of $S$ phase on mitosis. Nature 1991, 349:388-393.

24. Hayles J, Fisher D, Woollard A, Nurse P: Temporal order of $\mathbf{S}$ phase and mitosis in fission yeast is determined by the state of the p34cdc2-mitotic B cyclin complex. Cell 1994, 78:813-822. 
25. Correa-Bordes J, Nurse P: p25rum I orders $\mathbf{S}$ phase and mitosis by acting as an inhibitor of the p34cdc2 mitotic kinase. Cell 1995, 83:1001-1009.

26. Moreno S, Nurse P: Regulation of progression through the G phase of the cell cycle by the rum I+ gene. Nature 1994, 367:236-242.

27. Dahmann C, Diffley JF, Nasmyth KA: S-phase-promoting cyclindependent kinases prevent re-replication by inhibiting the transition of replication origins to a pre-replicative state. Curr Biol 1995, 5: 1 257-1269.

28. Stern B, Nurse P: A quantitative model for the cdc2 control of $S$ phase and mitosis in fission yeast. Trends Genet 1996 , I 2:345-350.

29. Perry JA, Kornbluth S: Cdc25 and Weel: analogous opposites? Cell Div 2007, 2:12.

30. Bloom J, Cross FR: Multiple levels of cyclin specificity in cellcycle control. Nat Rev Mol Cell Biol 2007, 8: I49-I60.

31. Loog M, Morgan DO: Cyclin specificity in the phosphorylation of cyclin-dependent kinase substrates. Nature 2005, 434: $104-108$.

32. Nguyen VQ, Co C, Li Jj: Cyclin-dependent kinases prevent DNA re-replication through multiple mechanisms. Nature 200I, 4I I:1068-1073.

33. Zegerman P, Diffley JF: Phosphorylation of SId2 and SId3 by cyclin-dependent kinases promotes DNA replication in budding yeast. Nature 2007, 445:28I-285.

34. Itzhaki JE, Gilbert CS, Porter AC: Construction by gene targeting in human cells of a "conditional' CDC2 mutant that rereplicates its DNA. Nat Genet 1997, 15:258-265.

35. Cai D, Latham VM Jr., Zhang X, Shapiro Gl: Combined depletion of cell cycle and transcriptional cyclin-dependent kinase activities induces apoptosis in cancer cells. Cancer Res 2006, 66:9270-9280

36. Laronne A, Rotkopf S, Hellman A, Gruenbaum Y, Porter AC, Brandeis $M$ : Synchronization of interphase events depends neither on mitosis nor on cdkI. Mol Biol Cell 2003, I 4:3730-3740.

37. Gupta M, Trott $D$, Porter AC: Rescue of a human cell line from endogenous Cdk I depletion by Cdk I lacking inhibitory phosphorylation sites. J Biol Chem 2007, 282:430I-4309.

38. Badie C, Itzhaki JE, Sullivan MJ, Carpenter AJ, Porter AC: Repression of CDKI and other genes with CDE and CHR promoter elements during DNA damage-induced $\mathbf{G ( 2 ) / M}$ arrest in human cells. Mol Cell Biol 2000, 20:2358-2366.

39. Donzelli M, Draetta GF: Regulating mammalian checkpoints through Cdc25 inactivation. EMBO Rep 2003, 4:67I-677.

40. de Toledo SM, Azzam El, Keng P, Laffrenier S, Little JB: Regulation by ionizing radiation of $C D C 2$, cyclin $A$, cyclin $B$, thymidine kinase, topoisomerase Ilalpha, and RAD5 I expression in normal human diploid fibroblasts is dependent on p53/p2 I Wafl Cell Growth Differ 1998, 9:887-896.

41. Niculescu AB 3rd, Chen X, Smeets M, Hengst L, Prives C, Reed SI: Effects of p2 I (Cip I/WafI) at both the GI/S and the G2/M cel cycle transitions: $p R b$ is a critical determinant in blocking DNA replication and in preventing endoreduplication. Mo Cell Biol 1998, I 8:629-643.

42. Bates S, Ryan KM, Phillips AC, Vousden KH: Cell cycle arrest and DNA endoreduplication following p2IWafI/Cipl expression. Oncogene 1998, 17:1691-1703.

43. Bellanger S, de Gramont A, Sobczak-Thepot J: Cyclin B2 suppresses mitotic failure and DNA re-replication in human somatic cells knocked down for both cyclins B I and B2. Oncogene 2007, 26:7|75-7I84.

44. L'Italien L, Tanudji M, Russell L, Schebye XM: Unmasking the redundancy between CdkI and Cdk2 at $\mathbf{G 2}$ phase in human cancer cell lines. Cell Cycle 2006, 5:984-993.

45. Guadagno TM, Newport JW: Cdk2 kinase is required for entry into mitosis as a positive regulator of Cdc2-cyclin B kinase activity. Cell 1996, 84:73-82.

46. Berthet C, Kaldis P: Cdk2 and Cdk4 cooperatively control the expression of Cdc2. Cell Div 2006, I: 10.

47. Liu E, Li X, Yan F, Zhao Q, Wu X: Cyclin-dependent kinases phosphorylate human $\mathrm{CdtI}$ and induce its degradation. J Biol Chem 2004, 279: $17283-17288$.

48. Sugimoto N, Tatsumi Y, Tsurumi T, Matsukage A, Kiyono T, Nishitan $H$, Fujita $M$ : CdtI phosphorylation by cyclin A-dependent kinases negatively regulates its function without affecting geminin binding. J Biol Chem 2004, 279: 1969|-19697.

49. Takeda DY, Parvin JD, Dutta A: Degradation of Cdt I during S phase is Skp2-independent and is required for efficient progression of mammalian cells through $\mathbf{S}$ phase. J Biol Chem 2005, 280:234I6-23423.

50. Nishitani H, Sugimoto N, Roukos V, Nakanishi Y, Saijo M, Obuse C Tsurimoto T, Nakayama KI, Nakayama K, Fujita M, Lygerou Z, Nishimoto T: Two E3 ubiquitin ligases, SCF-Skp2 and DDB I-Cul4, target human Cdt I for proteolysis. Embo / 2006, 25: I | 26- I I 36

5I. Saha P, Chen J, Thome KC, Lawlis SJ, Hou ZH, Hendricks M, Parvin JD, Dutta A: Human CDC6/Cdcl 8 associates with Orcl and cyclin-cdk and is selectively eliminated from the nucleus at the onset of S phase. Mol Cell Biol 1998, I 8:2758-2767.

52. Fujita M, Yamada C, Goto H, Yokoyama N, Kuzushima K, Inagaki M, Tsurumi T: Cell cycle regulation of human CDC6 protein. Intracellular localization, interaction with the human $\mathrm{mcm}$ complex, and CDC2 kinase-mediated hyperphosphorylation. J Biol Chem 1999, 274:25927-25932.

53. Jiang W, Wells NJ, Hunter T: Multistep regulation of DNA replication by Cdk phosphorylation of HsCdc6. Proc Natl Acad Sci U S A 1999, 96:6193-6198.

54. Petersen BO, Lukas J, Sorensen CS, Bartek J, Helin K: Phosphorylation of mammalian CDC6 by cyclin A/CDK2 regulates its subcellular localization. Embo J I999, I 8:396-4I0.

55. Vaziri C, Saxena S, Jeon Y, Lee C, Murata K, Machida Y, Wagle N Hwang DS, Dutta A: A p53-dependent checkpoint pathway prevents rereplication. Mol Cell 2003, I I:997-1008.

56. Hamaguchi JR, Tobey RA, Pines J, Crissman HA, Hunter T, Bradbury EM: Requirement for $\mathbf{p 3 4 c d c 2}$ kinase is restricted to mitosis in the mammalian cdc2 mutant FT210. I Cell Biol 1992, I 1 7:1041-1053.

57. Vassilev LT, Tovar C, Chen S, Knezevic D, Zhao X, Sun H, Heimbrook DC, Chen L: Selective small-molecule inhibitor reveals critical mitotic functions of human CDKI. Proc Natl Acad Sci U S A 2006, I03:10660-10665.

58. Melixetian M, Helin K: Geminin: a major DNA replication safeguard in higher eukaryotes. Cell Cycle 2004, 3: $1002-1004$

59. Saxena S, Dutta A: Geminin-Cdtl balance is critical for genetic stability. Mutat Res 2005, 569: || |-|2|

60. Machida YJ, Dutta A: The APC/C inhibitor, Emi I, is essential for prevention of rereplication. Genes Dev 2007, 2 I : I 84-194.

61. Melixetian M, Ballabeni A, Masiero L, Gasparini P, Zamponi R, Bartek J, Lukas J, Helin K: Loss of Geminin induces rereplication in the presence of functional p53. I Cell Biol 2004, 165:473-482.

62. Zhu W, Chen Y, Dutta A: Rereplication by depletion of geminin is seen regardless of p53 status and activates a G2/M checkpoint. Mol Cell Biol 2004, 24:7|40-7|50.

63. Jin J, Arias EE, Chen J, Harper JW, Walter JC: A family of diverse Cul4-Ddbl-interacting proteins includes Cdt2, which is required for $\mathbf{S}$ phase destruction of the replication factor CdtI. Mol Cell 2006, 23:709-72I.

64. Lovejoy CA, Lock K, Yenamandra A, Cortez D: DDB I maintains genome integrity through regulation of Cdtl. Mol Cell Biol 2006, 26:7977-7990.

65. Nishitani H, Lygerou Z Nishimoto T. Proteolysis of DNA replication licensing factor Cdt I in S-phase is performed independently of geminin through its $\mathbf{N}$-terminal region. J Biol Chem 2004, 279:30807-30816.

66. Kulartz M, Knippers $\mathrm{R}$ : The replicative regulator protein geminin on chromatin in the HeLa cell cycle. I Biol Chem 2004 279:4I686-4I694.

67. Gonzalez MA, Tachibana KE, Adams DJ, van der Weyden L, Hemberger M, Coleman N, Bradley A, Laskey RA: Geminin is essential to prevent endoreduplication and to form pluripotent cells during mammalian development. Genes Dev 2006 20: $\mid 880-1884$.

68. Reimann JD, Freed E, Hsu JY, Kramer ER, Peters JM, Jackson PK: Emil is a mitotic regulator that interacts with Cdc20 and inhibits the anaphase promoting complex. Cell 200I, 1 05:645-655

69. Hsu JY, Reimann JD, Sorensen CS, Lukas J, Jackson PK: E2F-dependent accumulation of $\mathrm{hEmil}$ regulates $S$ phase entry by inhibiting APC(Cdh I). Nat Cell Biol 2002, 4:358-366

70. Miller IJ, Summers MK, Hansen DV, Nachury MV, Lehman NL, Loktev $A$, Jackson PK: Emil stably binds and inhibits the anaphase- 
promoting complex/cyclosome as a pseudosubstrate inhibitor. Genes Dev 2006, 20:2410-2420.

7I. Hansen DV, Loktev AV, Ban KH, Jackson PK: PIkI regulates activation of the anaphase promoting complex by phosphorylating and triggering SCFbetaTrCP-dependent destruction of the APC Inhibitor Emi I. Mol Biol Cell 2004, I5:5623-5634.

72. Di Fiore B, Pines J: Emil is needed to couple DNA replication with mitosis but does not regulate activation of the mitotic APC/C. J Cell Biol 2007, 177:425-437.

73. Sivaprasad U, Machida YJ, Dutta A: APC/C--the master controller of origin licensing? Cell Div 2007, 2:8.

Publish with Biomed Central and every scientist can read your work free of charge

"BioMed Central will be the most significant development for disseminating the results of biomedical research in our lifetime. "

Sir Paul Nurse, Cancer Research UK

Your research papers will be:

- available free of charge to the entire biomedical community

- peer reviewed and published immediately upon acceptance

- cited in PubMed and archived on PubMed Central

- yours - you keep the copyright

Submit your manuscript here:

http://www.biomedcentral.com/info/publishing_adv.asp
BioMedcentral 